\title{
Neuro-COVID-19: an insidious virus in action
}

\author{
Jolanta Bratosiewicz-Wąsik \\ Department of Biopharmacy, Faculty of Pharmaceutical Sciences in Sosnowiec, Medical University of Silesia in Katowice, Poland
}

\begin{abstract}
Introduction. The punishing effect of the pandemic outbreak of the disease termed COVID-19 (coronavirus disease-19) caused by severe acute respiratory syndrome coronavirus type 2 (SARS-CoV-2) impelled the author to gather the facts about the nature of this new pathogen. The aim of this paper was to discuss the mechanisms involved in the pathogenesis of neurological complications during the course of COVID-19.

State of the art. Neurological symptoms, such as impairment of taste or smell, headache, nausea and/or altered consciousness, are commonly described in COVID-19 patients, although there are emerging clinical reports of more serious conditions such as acute cerebrovascular accidents, encephalitis and demyelinating disease. Whether these manifestations are the direct consequence of viral invasion of the central nervous system, or are caused by indirect mechanisms, is yet to be established. Studies to date have indicated that neurological lesions found in the brains of COVID-19 patients are a combination of direct cytopathic effects caused by SARS-CoV-2 replication and indirect effects due to hypoxia, excessive cytokine reaction, impaired immune response, and cerebrovascular injury induced by viral infection. Studies are still pending into possible routes of SARS-CoV-2 neuroinvasion encompassing the haematopoietic pathway via the blood-brain barrier and retrograde axonal transport through the cranial nerves.

Clinical implications. A thorough understanding of SARS-CoV-2 involvement in neurological complications is still lacking. However, our knowledge about SARS-CoV-2 virulence is rapidly expanding, and that has inclined the author to prepare this comprehensive review in the hope that it will improve understanding about the molecular mechanisms underlying neurological abnormalities associated with COVID-19.

Future directions. A future detailed study should explore the diagnostics and disease mechanisms so as to enable the development of better therapeutic strategies to reduce the severity of COVID-19 neurological complications.
\end{abstract}

Key words: coronavirus, COVID-19, SARS-CoV-2, CNS complications

(Neurol Neurochir Pol 2022; 56 (1): 48-60)

\section{Introduction}

The global pandemic of coronavirus disease 2019 (COVID-19) caused by severe acute respiratory syndrome coronavirus type 2 (SARS-CoV-2) began at the end of 2019 in Wuhan, China [1]. Because of the rapid and global spread of the virus in humans, on 11 March, 2020, the World Health Organisation decided that COVID-19 should be categorised as a pandemic [2]. At the time of writing, 200,840,180 laboratory-confirmed cases of COVID-19 have been reported, with 4,265,903 deaths worldwide [3].
Comparison of the full-length genome sequence of SARSCoV-2 and other available genomes of coronaviruses indicates that the closest relationship of SARS-CoV-2 is with bat SARSlike coronavirus strain BatCov RaTG13, being 96\% identical, which suggests that SARS-CoV-2 might have naturally evolved from bat coronavirus RaTG13 [4].

The clinical course of the SARS-CoV-2 infection is very diverse, ranging from asymptomatic to severe pneumonia, septic shock, pulmonary oedema, acute respiratory distress symptom, and multiorgan dysfunction, with an estimated case fatality rate of about $2.3 \%[5,6]$. The most common symptoms

Address for correspondence: Jolanta Bratosiewicz-Wąsik, Department of Biopharmacy, Faculty of Pharmaceutical Sciences in Sosnowiec, Medical University of Silesia in Katowice, 41-200 Sosnowiec, Jedności 8 Str., Katowice, Poland; e-mail: jbrat@sum.edu.pl

Received: 10.08.2021 Accepted: 7.09.2021 Early publication date: 13.10.2021

This article is available in open access under Creative Common Attribution-Non-Commercial-No Derivatives 4.0 International (CC BY-NC-ND 4.0) license, allowing to download articles and share them with others as long as they credit the authors and the publisher, but without permission to change them in any way or use them commercially. 
of COVID-19 comprise fever, chills, myalgia, fatigue, dry cough, dizziness, headache, diarrhoea, nausea, and vomiting, and seem to be strain dependent [7]. Furthermore, anosmia and ageusia have been qualified as COVID-19 distinguishing symptoms [8]. Patients with underlying comorbidities such as hypertension, diabetes, cardiovascular disorders and cerebrovascular diseases are more vulnerable to a severe course of COVID-19, with higher mortality rates $[9,10]$. Currently, there are an increasing number of clinical observations in individuals infected with SARS-CoV-2 denoting its capacity to invade the central nervous system (CNS) and peripheral nervous system (PNS). Analysis of COVID-19's neurological manifestations, as well as better understanding of the mechanisms of the nervous system invasion and destruction caused by SARS-CoV-2, could help to reduce the severity of the neurological complications.

To prepare this review article, a comprehensive literature search was performed using the PubMed and Google Scholar databases to identify relevant papers, published only in English and with no time limit. The following terms were searched: 'COVID-19', 'coronavirus', 'SARS', 'MERS', 'severe acute respiratory syndrome coronavirus', and 'SARS-CoV-2,' with combinations including 'neurotropism,', 'neurology', 'neurological manifestation', 'neuroinvasion', and 'nervous system.'
Moreover, the bibliographies of located papers were screened and cross-referenced to further identify relevant literature. The aim of the search was to find original research studies, case reports, retrospective studies, and review articles enabling the presentation of the pathogenesis of neurological complications during the course of COVID-19.

\section{SARS-CoV-2 characteristics}

SARS-CoV-2 is a positive-sense single strand RNA virus belonging to the Betacoronavirus genus of the Nidovirales order [11]. SARS-CoV-2 genome encodes 15 or 16 nonstructural proteins that form a replicase-transcriptase complex, four structural proteins in the gene order of spike (S), envelope $(\mathrm{E})$, membrane $(\mathrm{M})$, and nucleocapsid $(\mathrm{N})$, as well as nine accessory proteins (Fig. 1) [12-14]. The genomic RNA is encapsidated by the nucleocapsid protein which is crucial for enhancing the efficiency of virus transcription and assembly and for the host cellular response to viral infection. The nucleocapsid is enveloped by a phospholipid membrane, which comprises membrane, envelope, and spike proteins [15]. Because of the genome similarity between SARSCoV-2 and SARS-CoV, some parallels may be justified in terms of the mechanisms of infection, replication, and pathology

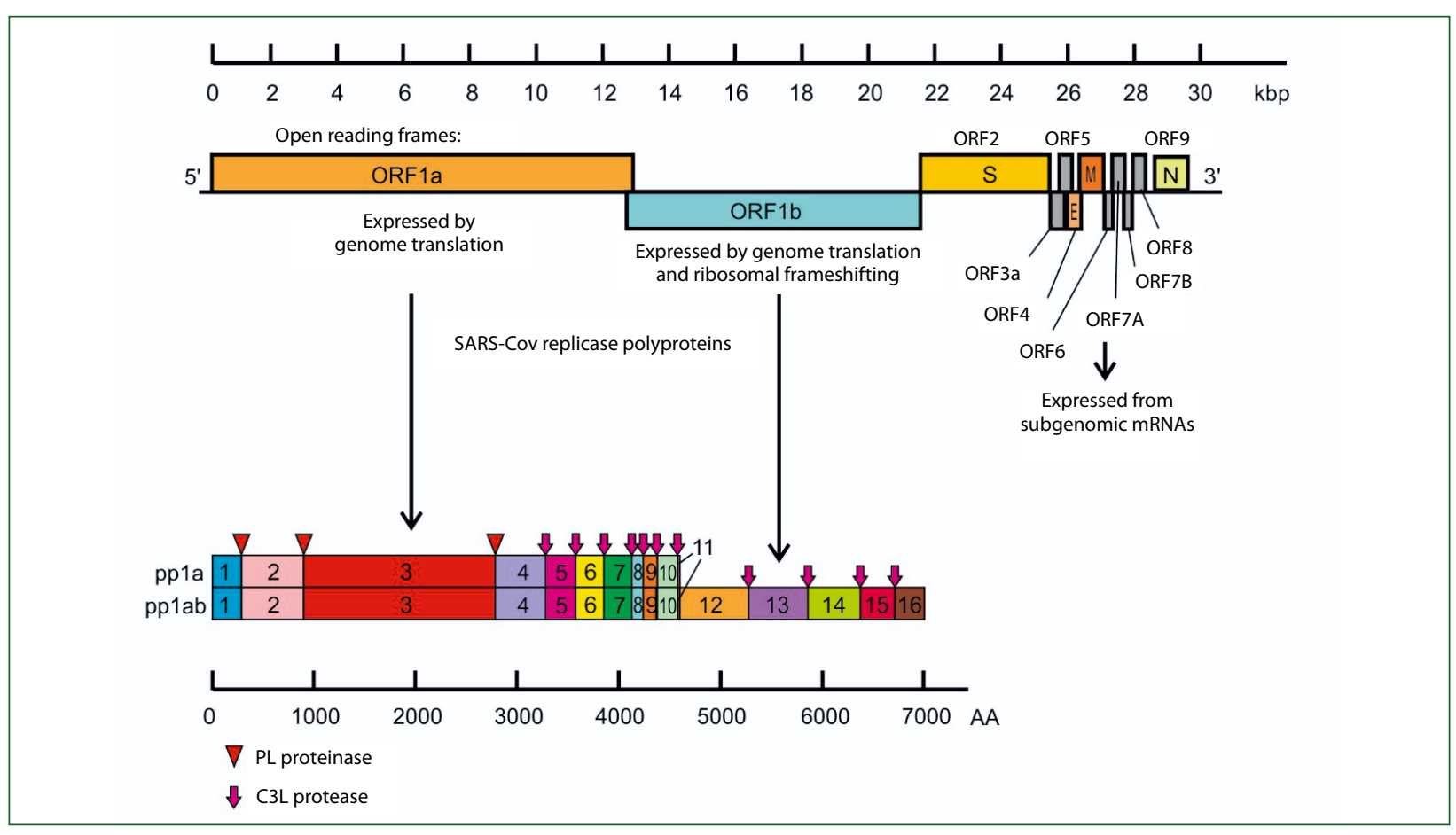

Figure 1. Coronaviruses genome organisation. Localised from 5' end there are two open reading frames (ORF) ORF1a, ORF1b, which encode polyproteins pp1a and pp1ab that are sequentially cleaved to release 16 or sometimes 15 functional nonstructural proteins constituting replication-transcription complex (RTC). ORFs localised at 3' end encode structural and regulatory proteins: spike (S), ORF3A, envelope (E), membrane (M), ORF5, ORF6, ORF7A, ORF7B, ORF8, and nucleocapsid (N). Bottom panel shows proteolytic processing of pp1a and pp1ab polyproteins. Numbers of polyprotein pp1a and pp1ab segments correspond to nonstructural proteins: 3 - PLpro, papain-like proteinase; 5 - 3CLpro, 3C-like protease; 12 - RdRp, RNA-dependent RNA polymerase; 13 - HEL1, superfamily 1 helicase; 14 - ExoN, exoribonuclease, N7-MT, N7-methyl transferase; 15 - endoU, uridylate-specific endoribonuclease; 16 - 2'-0-MT, 2'-0-methyl transferase [12] 
between SARS-CoV-2 and SARS-CoV. Replication of SARS$\mathrm{CoV}-2$ starts from recognition of its receptors on the surface of host cells. This step is mediated by SARS-CoV-2 S protein which binds to the cellular angiotensin-converting enzyme 2 (ACE2) via its receptor-binding domain (RBD) [4] and is followed by fusion between viral and cellular membrane releasing the viral genome into the cytoplasm. The activity of the spike protein is assured by its proteolytic processing at two sites: the first cleavage releasing the S1 and S2 subunits is caused by furin and enables interaction between RBD and ACE2, whereas the second cleavage at the S2' site is performed by transmembrane serine protease 2 (TMPRSS2) or cathepsin $\mathrm{L}$ and facilitates the virus-cell membrane fusion $[16,17]$. After uncoating, the virus genome is used as a template to produce the non-structural proteins forming replicase-transcriptase complex (RTC) which in turn synthesises subgenomic RNAs for structural proteins (N, S, E, and M). N protein encapsidates viral genome forming nucleocapsid, and finally the virus particle comes out of the endoplasmic reticulum-Golgi intermediate compartment, where the new virion gains its envelope with incorporated proteins $\mathrm{M}, \mathrm{E}$, and $\mathrm{S}$ and is released by exocytosis $[18,19]$.

\section{Host factors enabling entry of SARS-CoV-2 into cell}

Recognition of the cellular receptor and virus binding with the structures on the cell surface is the critical step during the viral replication cycle: these interactions determine its cellular tissue, and species tropism, as well as the efficiency of the replication. This step is mediated by the viral spike protein, which recognises cellular receptor angiotensin-converting enzyme 2 [20]. The ability of the spike protein to bind the receptor is ensured by its proteolytic processing known as 'priming' - unleashing the S1 subunit and causing change of the RBD conformation that displays amino acids interacting with ACE2. This initial cleavage is followed by proteolysis at the S2' site, a process known as 'triggering', which exposes the fusion peptide and elicits the major, irreversible, conformational changes of the $S$ protein essential for membrane fusion and infection [21].

There is a variety of proteases capable of priming and triggering coronavirus (CoV) S proteins. Prediction studies suggest that the efficient priming of the SARS-CoV-2 S protein is made by furin. However, it has been suggested that non-furin proteases can process the SARS-CoV-2 'furin-like' S1/S2 site depending on the cell type [22]. Compared to priming, triggering seems to be more complicated; it has been observed that the CoV S protein can be triggered by proteases at the plasma membrane or endosomal membrane, enabling entry by so called 'early' and 'late' pathways, respectively [23]. SARSCoV-2 has been found to utilise the transmembrane bound protease TMPRSS2, or endosomal cathepsin L, for cell entry via the early and late pathways, respectively $[16,17]$.
To date, studies on SARS-CoV-2 entry have focused almost entirely on binding with ACE2, expressed at very low levels in respiratory and olfactory epithelial cells which were found infected in the majority of COVID-19 patients. This indicates that some cofactors are required to facilitate virus-host cell interactions in cells with low ACE2 expression. Neuropilin 1 (NRP1) has been proposed as such an ACE2 potentiating factor by promoting the interaction of the virus with ACE2.

Thus, research has focused on identifying additional factors which may increase SARS-CoV-2 infectivity and influence its tissue tropism, and, in consequence, elucidate COVID-19 pathophysiology, especially the existence of extra-pulmonary manifestations e.g. neurological and gastrointestinal symptoms. Daly et al. and Cantuti-Castelvetri et al. showed that furin cleavage of S1/S2 motif generated Arg-Arg-Ala-Arg (RRAR) sequence fitting into a pocket on the b1 domain of the neuropilins. They showed that NRP1 promoted infection of human cell lines by SARS-CoV-2 and by lentivirus pseudotypes that contained the SARS-CoV-2 S protein on their surface. This reinforcement of SARS-CoV-2 infectivity was blocked by a monoclonal blocking antibody against NRP1 [24]. An examination of NRP1 expression using single cell RNA sequencing performed by Davies et al. demonstrated that the NRP1 is expressed in the CNS, including olfactory-related regions such as the olfactory tubercle and paraolfactory gyri. It has been shown that in the human brain, mature astrocytes express NRP1 at the highest levels, endothelial and microglia/macrophage express NRP1 at moderate levels, whereas oligodendrocytes express NRP1 at the lowest levels [25]. Interestingly, in vivo studies have shown the uptake of nanoparticles coated with SARS-CoV-2-derived NRP-1 binding peptides into the olfactory epithelium and into neurons and blood vessels of the cortex [24].

In addition to ACE2, Wang et al. demonstrated that SARSCoV-2 spike protein binds to CD147, also known as Basigin (BSG) or extracellular matrix metalloproteinase inducer (EMMPRIN). Previously, CD147 was shown to play a functional role in facilitating SARS-CoV invasion of the host cells [26]. Interestingly, expression of ACE2 is lower, but expression of CD147 is higher, in most human and mouse brain cell lines, and mouse brain tissues, compared to lung cell lines. This indicates that SARS-CoV-2 might use different pathways for cell entry into the cerebral nervous system [27].

\section{Neurological symptoms of COVID-19}

The main symptoms of SARS-CoV-2 infection, such as fever, dry cough, and dyspnoea, are accompanied by signs of invasion of extrapulmonary organs and, in severe cases, this infection can progress to multiorgan failure and death. Since the beginning of the COVID-19 pandemic, growing evidence has indicated that patients with SARS-CoV-2 may develop neurological symptoms (Tab. 1) [7, 28]. It has been established that the major factors associated with the neurological 
Table 1. Neurological manifestations of COVID-19

\begin{tabular}{l} 
Central nervous system: \\
Dizziness \\
Headache \\
Impaired consciousness \\
Acute cerebrovascular disease \\
Ataxia \\
Seizures \\
Anosmia \\
Ageusia \\
Vision impairment \\
Neuralgia \\
Ryabdomyolysis \\
\hline
\end{tabular}

complications of SARS-CoV-2 infection were firstly age over 60 , and secondly a history of neurological conditions. Additionally, in subjects with COVID-19 at the same level of severity, the new-onset of neurological critical events increased the risk of death six-fold [29]. The earliest report on detailed neurological manifestations of hospitalised patients with COVID-19 in Wuhan, China, revealed that more than one in three of them had some neurological manifestations. The types of neurological symptoms were classified into three categories: central, peripheral, and musculoskeletal. Central symptoms comprise impaired consciousness, acute cerebrovascular disease, (both of which are found more frequently among patients with severe disease outcome), in addition to ataxia, seizure, dizziness and headache. The commonest peripheral symptoms were impairment of taste or smell, whereas vision impairment and nerve pain were observed less often. Skeletal muscle injury is related to the severity of disease (19.3\% in severe vs. $4.8 \%$ in nonsevere infection) [30]. A different stratification of neurological symptoms was performed in a retrospective multicentre cohort study of 917 patients with COVID-19 treated in COVID-19 treatment centres from $\mathrm{Hu}-$ bei and Sichuan provinces as well as Chongqing municipality in China. Here, specific new-onsets of neurological events were grouped into 'critical' and 'noncritical' new neurological events. This report revealed that the frequency of new-onset critical neurological events, including impaired consciousness or stroke, was $3.5 \%$ overall and $9.4 \%$ among those with severe or critical COVID-19. Noncritical events, including muscle cramp, unexplained headache, occipital neuralgia, tic, and tremor, were seen in less than $1 \%$ of cases [30]. Another study in France noted neurological symptoms in 49/58 patients. These included agitation, confusion, diffuse corticospinal tract signs, and dysexecutive syndrome [31]. Brain MRI performed in ICU (intensive care unit) patients with neurological symptoms revealed abnormalities in $44 \%$ of them [32].

A growing number of reports indicate that neurological conditions and post-viral triggered autoimmune complications such as Guillain-Barre syndromes (GBSs), myopathy and rhabdomyolysis, encephalopathy, meningoencephalitis, encephalomyelitis, and myelitis, occur in association with the SARS-CoV-2 infection [33].

Several clinical studies in Poland have reported neurological abnormalities in most hospitalised patients with COVID-19. An evaluation of the frequency and spectrum of neurological symptoms in COVID-19 patients performed in the University Hospital in Kraków showed that the commonest neurological symptoms were: fatigue $(62.5 \%)$, worse mood (45.5\%), myalgia (43.5\%), muscle weakness (42.5\%) and headache (37.0\%). Anosmia and ageusia were reported in $21.5 \%$ and $27 \%$ of patients, respectively. Moreover, analysis of a possible association of neurological symptoms with in-hospital mortality revealed that a decreased level of consciousness and delirium were linked to a higher risk of death during hospitalisation [34].

In another clinical study of 100 patients with COVID-19 hospitalised in the University Hospital in Kraków, neurological manifestations including myalgia (27\%) and dysgeusia or dysosmia (15\%) were observed [35]. Neurological symptoms were also observed in children infected with SARS-CoV-2 tested by the Regional Sanitary-Epidemiological Station in Poznań. The commonest clinical symptoms in the group of 94 children were dysgeusia and anosmia, which were present in $75.5 \%$, and headaches, observed in $49 \%$ of patients [36]. Moreover, two uncommon neurological manifestations associated with COVID-19 have been documented in Poland. Przytuła et al. reported ataxia-myoclonus syndrome, isolated myoclonus, and opsoclonus-myoclonus syndrome in two COVID-19 patients and postulated the autoimmune symptoms' background [37]. Cutaneous hyperaesthesia, lasting from one day to several months, was described by Krajewski et al. in nine COVID-19 patients [38].

\section{COVID-19-related pathophysiology in CNS}

\section{Direct invasion}

Neuroinvasive propensity has been demonstrated as a common feature of CoVs. In light of the high genetic and behavioural similarity between SARS-CoV and SARS-CoV-2, it is clear that SARS-CoV-2 also possesses similar potential. The foremost factor enabling viral infectivity is the receptor recognition by virus surface protein, which in turn should have a specific arrangement of amino acids for effective binding with the host cell. SARS-CoV-2 has been shown to have a strong 


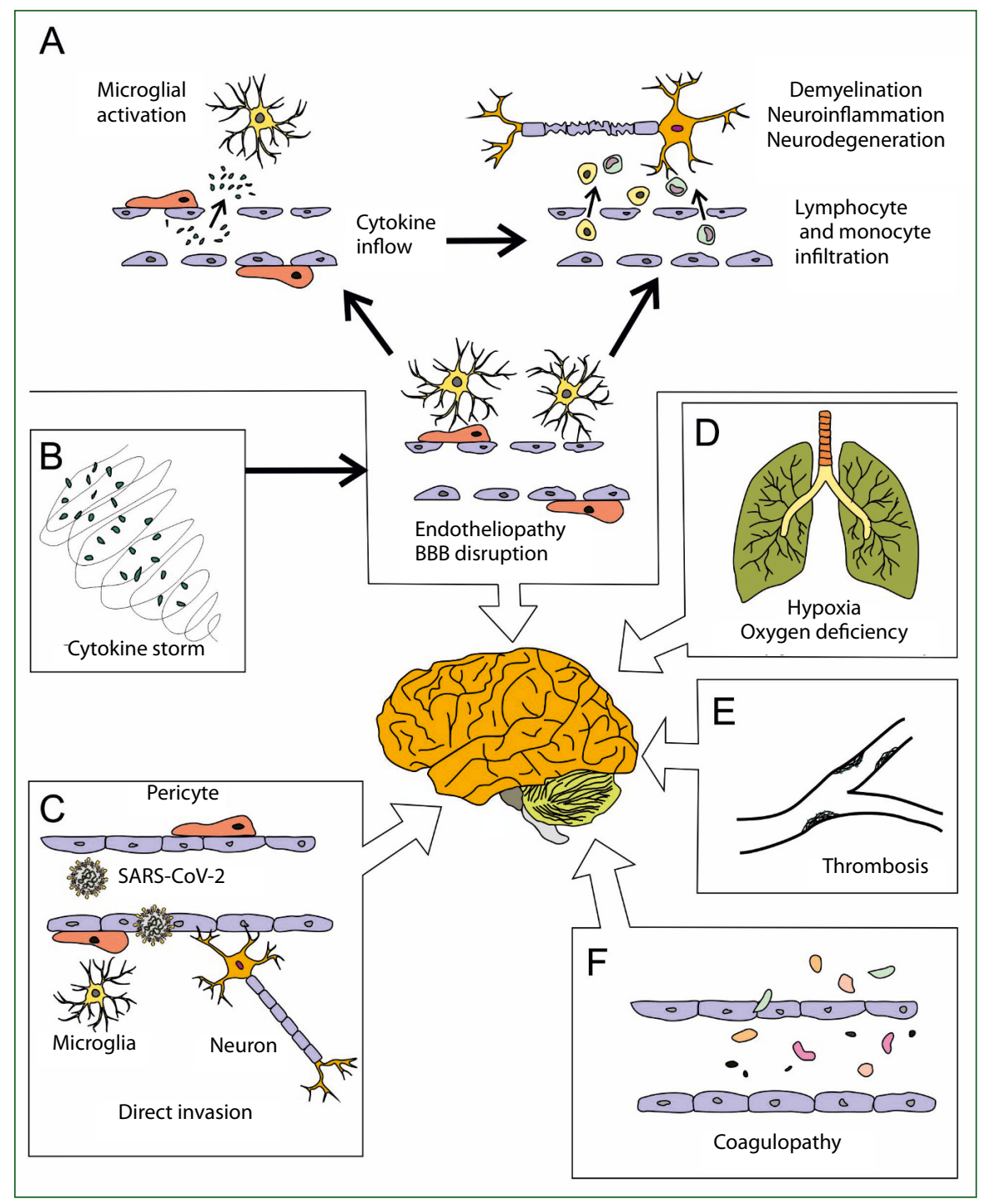

Figure 2. Possible mechanisms of neurological manifestations of SARS-CoV-2 infection. A. Caused by cytokine storm (B) endotheliopathy and BBB dysfunction, leads to inflow of lymphocytes and monocytes which contribute to demyelination, neuroinflammation, and neurodegeneration. On other hand, disruption of BBB results in cytokine inflow and microglial activation; C. Infection of endothelial cells makes it possible for SARS-CoV-2 to invade brain and infect both neurons and microglial cells; D. Respiratory depression triggers brain hypoxia leading to accumulation of anaerobic metabolism products, inflammation, and ultimately cell death; E. Thrombosis of brain blood vessels and blood hyper-viscosity induced by proinflammatory cytokines lead to ischaemic stroke; F. Coagulopathy in combination with endotheliopathy causes haemorrhagic stroke

affinity towards the human ACE2 receptor [16]. ACE2 is expressed in multiple tissues in the human body, including non-neuronal cells of the olfactory epithelium and olfactory bulb [39], as well as glial cells and neurons in the CNS [40]. Thus, if the virus gets into the nervous system, neurons and glial cells would serve as SARS-CoV-2 replication sites (Fig. 2). The exact way of reaching the nervous system is one the great unknowns of neuropathogenesis of SARS-CoV-2 infection. One possibility is viral transport from the endothelium to olfactory nerves and bulb and finally to the brain, although a haematopoietic pathway is possible as well [41].
Increasing evidence of SARS-CoV-2 neuroinvasion has been obtained from cerebrospinal fluid tests, postmortems, and experimental studies. The detection of SARS-CoV-2 RNA in CSF was reported for the first time by Moriguchi et al. in Japan on 8 March, 2020 [42]. However, since then, only a few cases of SARS-CoV-2 in CSF of COVID-19 patients have been reported, as reviewed by Liu et al. [43]. To date, autopsy studies performed on the brains of COVID-19 patients have revealed SARS-CoV-2 in different parts of the brain, including frontal lobes, olfactory nerve, olfactory bulb, trigeminal ganglion, medulla oblongata, cerebellum, and frontal cortex [44-46]. 
Using transmission electron microscopy, Paniz-Mondolfi et al. observed pleomorphic spherical viral-like particles individually and in small vesicles of endothelial cells, as well as cytoplasmic vacuoles containing enveloped viral particles in neural cell bodies [44]. Coronavirus infection of endothelial cells and neurons has been proved to cause their damage and apoptosis $[47,48]$. Moreover, SARS-CoV-2 infection has been found within the regions of micro-ischaemic infarcts, suggesting the possibility of neuroinvasion-associated ischaemia and vascular anomalies [49].

Evidence provided by studies performed using a $3 \mathrm{D}$ microfluidic model of the human blood-brain barrier (BBB) demonstrated that the SARS-CoV-2 spike protein promoted loss of barrier integrity, which suggests that the $S$ protein triggers a pro-inflammatory response of brain endothelial cells that may contribute to an altered state of BBB function [50]. In experimental studies, SARS-CoV-2, but not SARS$\mathrm{CoV}$, was shown to replicate in U251 (neuronal) cells, but at a relatively low level [51]. SARS-CoV-2 neurotropism was also supported by its presence in neurons and other neuronal cells of human brain organoids exposed to the virus $[49,52]$. Moreover, brain organoids could model CNS pathologies of COVID-19 since imaging neurons of organoids exposed to SARS-CoV-2 revealed altered distribution of Tau from axons to soma, hyperphosphorylation, and apparent neuronal death [52].

To demonstrate SARS-CoV-2 neuroinvasive potential, and to clarify the pathophysiology of COVID-19, several animal models for SARS-CoV-2 infection have been developed. A gradual increase of SARS-CoV-2 titres in the brain tissue from day 2 to days 5 and 6 postinfection was reported by Rathnasinghe et al. and Zheng et al. in K18-hACE2 mice $[53,54]$. Using the same strain of transgenic mice, Yinda et al. revealed that SARS-CoV-2 could enter the cerebral cortex and hippocampus after intranasal inoculation. In these regions, SARS-CoV-2 antigen was present in neurons and glial cells along the soma and axons of infected neurons [55].

\section{ACE2}

SARS-CoV-2 uses ACE2 to bind to the host cells with high affinity, and this very specific interaction may contribute to the ease with which SARS-CoV-2 spreads from human to human [27]. It has been proved that ACE2 and TMPRSS2 are expressed not only in the cells and tissues of lungs, but also in extrapulmonary organs including the heart, kidneys, liver, digestive tract, and brain [56]. ACE2 is widely distributed throughout the brain, and nuclear expression of ACE2 using a single-nucleus RNA-seq method has been found in many neurons and some non-neuron cells, mainly astrocytes, oligodendrocytes, and endothelial cells [57]. The highest ACE2 expression level was found in the pons and medulla oblongata of the human brainstem, where the medullary respiratory centres of the brain are localised. This may, at least in part, explain the susceptibility of many COVID-19 patients to severe respiratory distress [58]. It is worth noting that the ACE2 protein plays a dual role in COVID-19 pathology: it enables SARS-CoV-2 to enter host cells; and, on the other hand, the infection induces disturbances of its turnover and deprives organs of its protective function. In several studies, ACE2 has emerged as a potent negative regulator of the renin-angiotensin system (RAS), playing an opposing role to ACE in diverse organ systems including the brain [59]. Downregulation of ACE2 expression in the lungs was revealed by Kuba et al. in 2005, who proved that SARS-CoV infection, as well as a recombinant spike protein of SARS-CoV, reduced ACE2 expression [60]. This phenomenon leads to imbalance in the renin-angiotensin system and vasoconstriction, sodium and water retention, elevated blood pressure, and proinflammatory and procoagulation effects [61]. The protective role of ACE2 in the brain was demonstrated in a mouse model by Chen et al., who showed that neuronal overexpression of ACE2 protected the brain from ischaemic injury via the dysregulation of NADPH oxidase/eNOS (endothelial nitric oxide synthase) pathways caused by changing Ang (1-7)/Ang II ratio [62]. Moreover, a decreased amount of ACE2 and Ang (1-7) damaged cells in the cerebral arteries and enhanced the level of oxidative stress [63].

\section{Hypoxic injury}

Patients with a severe course of COVID-19 develop pneumonia, which causes respiratory depression leading to brain hypoxia. Reduction of oxygen delivery to the brain decreases production of the energy and leads to the accumulation of anaerobic metabolism products (e.g. lactic acid) in the CNS, oxidative stress, dysfunction of the blood brain barrier (BBB), cerebral vasodilation, swelling of neurons, obstruction of blood flow, inflammation, and ultimately cell death [64]. Brain post mortems of COVID-19 patients have revealed neuronal damage in the areas highly vulnerable to hypoxia such as the cerebral cortex, hippocampus, and cerebellum $[46,65,66]$. If the hypoxia continues, brain function gradually deteriorates and may elicit symptoms ranging from headache and temporary loss of memory to drowsiness, seizure, coma, and brain death [30,67].

\section{Stroke and coagulopathy}

COVID-19-associated coagulopathy (CAC), thrombosis, and disseminated intravascular coagulation (DIC) have emerged as crucial complications during a severe course of COVID-19, and are associated with a high mortality rate [68, 69]. Characteristic changes of coagulation parameters such as elevated levels of D-dimer and fibrinogen degradation products (FDPs), increased fibrinogen, and prolonged prothrombin time (PT), as well as alterations in platelet count, have been reported in patients with COVID-19 [69, 70]. The clinical presentation of COVID-19-associated coagulopathy is multi-organ failure, whereas haemorrhagic events are less frequent. Moreover, an increased incidence of arterial thromboses 
such as stroke and acute coronary syndromes has also been reported in COVID-19 patients [71]. Therefore, as expected, stroke-related imaging findings are among the most frequent abnormalities seen in patients with severe COVID-19. Among patients who displayed abnormal neuroimaging findings, territorial acute/subacute infarction, multiple ischaemic foci, evidence of thrombus in large intra- and extra-cranial vessels, cerebral venous thrombus complicated by haemorrhagic infarcts, and cortical/subcortical microhaemorrhages have been reported frequently in various observational studies $[72,73]$.

The pathophysiology of CAC is complex and differs in important ways from the standard mechanisms of thrombosis reported in critically ill patients. Several feasible mechanisms have been proposed as participating in stroke and CAC pathogenesis. Reported mechanisms of CAC include activated coagulation, endotheliopathy, up-regulated innate and adaptive immunity, and activated complement system [74]. ACE2 is heavily expressed in the myocardium, vascular endothelium, and arterial smooth muscle cells [75], making them susceptible to SARS-CoV-2 infection and endothelial injury and predisposing to thrombogenesis and stroke. Besides, SARS-CoV-2 induces a hyperinflammatory state, mediated by increased secretion of proinflammatory cytokines such as IL-1 and IL-6 responsible for supporting blood hyper-viscosity $[76,77]$. Activated by infection and injury, monocytes and endothelial cells release cytokines contributing to disseminated intravascular coagulation (DIC) along with the expression of tissue factor and secretion of von Willebrand factor [69]. Zuo et al. found elevated levels of serum neutrophil extracellular traps (NETs) markers such as cell-free DNA, MPO-DNA, and Cit-H3 in patients with COVID-19 [78]. Intravascular NETosis is responsible for the initiation and accretion of thrombotic events in arteries, veins, and the microvasculature where thrombotic disease can drive end organ damage in lungs, heart, kidneys, and other organs. In the brain, microvessel occlusion formed by intravascular thrombi can cause ischaemia and thus result in a partial or complete inhibition of organ function [79]. Furthermore, SARS-CoV-2 induces downregulation of ACE2 expression, which reduces its availability to convert Ang II into Ang (1-7) and leads to hyperactivation of classic RAS axis and vasoconstriction [80].

\section{Inflammatory response and immune dysfunction}

The activation of the immune system and consequent production of pro-inflammatory cytokines are crucial for natural immune responses. However, hyperactivation of the immune system, sometimes referred to as a 'cytokine storm', results in an excessive increase of levels of pro-inflammatory cytokines [81]. Acute respiratory distress syndrome (ARDS) is the result of a fatal, uncontrolled systemic inflammatory response, which is the consequence of the release of large amounts of pro-inflammatory cytokines and chemokines by immune effector cells in SARS-CoV-2 infection [7]. Interestingly, the level of neurovirulence of coronaviruses correlates with their differential ability to induce proinflammatory factors such as IL-6, IL-15, IL-1 $\beta$, and TNF- $\alpha$ in astrocytes and microglia, and brain immune cells responding to viral infection.

The release of a large amount of inflammatory factors induced by coronaviruses has been proposed as one of the pathophysiological processes responsible for CNS damage [82]. Comparisons between ICU (intensive care unit) and non-ICU patients showed that plasma concentrations of IL-2, IL-7, IL-10, GCSF, IP-10, MCP-1, MIP-1- $\alpha$, and TNF- $\alpha$ were higher in ICU patients than in non-ICU patients [7]. Thus, cytokines like IL-1, IL-6, TNF- $\alpha$, IFN- $\gamma$, chemokines like CCL2, and the acute phase protein CRP, that are either produced in the brain tissue or cross the blood-brain barrier, can disrupt the integrity of the $\mathrm{BBB}$ and modulate the functions of $B B B$ transporters such as P-glycoprotein [83, 84]. Cytokine storm leads to microglial activation and proliferation (MAP), neuronal death, disruption of synaptic plasticity, impairment of neurotransmitter metabolism, and predicts the subsequent occurrence of hippocampal atrophy $[85,86]$. Animal studies have shown that MAP releases pro-inflammatory cytokines and chemokines, upregulates inducible proinflammatory molecules, and promotes oxidative stress leading to breakage of endothelial tight junctions, which, in turn, allows the creation of feedback between the brain's innate and peripheral adaptive immunity $[87,88]$. Increased cytokine production (IL-6, TNF- $\alpha$, and IL-10) correlates with the reduction of peripheral $\mathrm{CD} 4+$ and $\mathrm{CD} 8+\mathrm{T}$ cells counts and with their hyperactivation expressed as coexpression of HLA-DR, CD38, and CD45RO activation markers [89, 90]. T-cell activation has been found to correlate with disease severity in COVID-19 patients as a higher frequency of activated CD8 $+\mathrm{T}$ cells (defined by CD38+ and HLA-DR+) occurred in severe patients a longer time after disease onset [91].

It also has been found that hyperactivation of $\mathrm{T}$ cells results in the upregulation of exhaustion markers such as TIM-3 (mucin domain-containing protein-3) mainly expressed on activated CD4+ Th1 cells and CD8+ cytotoxic T cells, PD1 (programmed cell death-1) mostly expressed on activated CD4+ T cells and CD8+ T cells, and NKG2A (C-type lectin-like receptor type $\mathrm{A}$, also known as $\mathrm{CD} 159$ ) expressed in NK and CD8+ T cells $[92,93]$. Activation of CD4+ and CD8+ cells may contribute to demyelination and axonal damage, as has been proved in mice infected with mouse hepatitis virus (MHV) [94].

\section{Routes of SARS-CoV-2 nervous system invasion}

SARS-CoV-2, like other coronaviruses, can infect different extrapulmonary tissues and organs including the central nervous system [41]. Neurotropism of SARS-CoV-2 is supported by the observation of neurological manifestations among patients with COVID-19 [31] as well as the detection of coronaviruses 


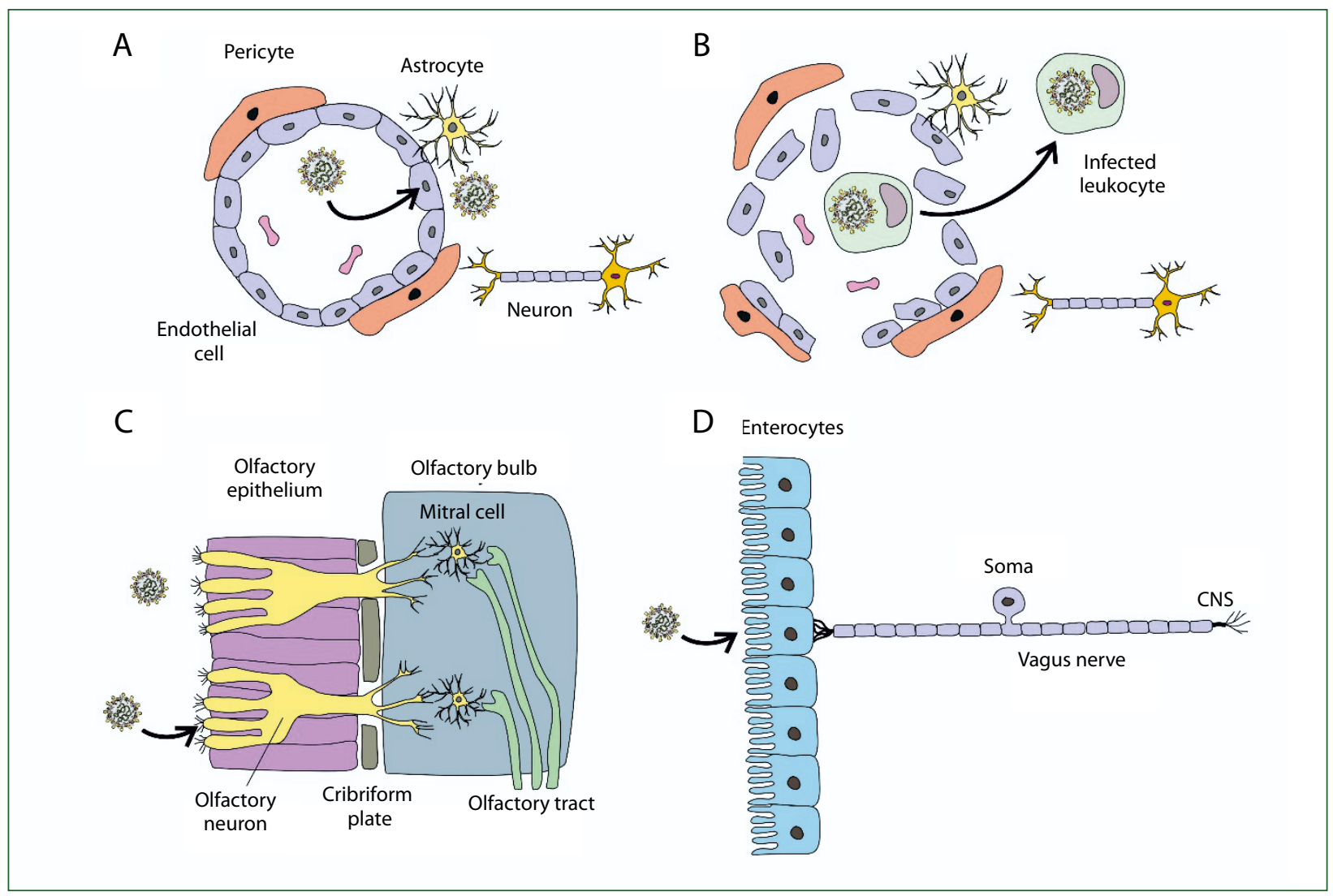

Figure 3. Potential routes of SARS-CoV-2 entry into central nervous system. A. SARS-CoV-2 infects endothelial cells and gains access to glial cells and neurons in CNS; B. Infected leukocytes cross disrupted BBB; C. SARS-CoV-2 infects olfactory epithelial cells and olfactory sensory neurons; D. SARS-CoV-2 infects gastrointestinal epithelium and invades vagus nerve

in neurological specimens $[95,96]$. Moreover, as previously mentioned in the section 'COVID-19-related pathophysiology in CNS', SARS-CoV-2 has been shown to have the capability to infect and kill neurons in 3D human brain organoids, and virions have been detected in different parts of the brains of COVID-19 patients.

The routes and mechanisms used by SARS-CoV-2 to invade the nervous system are still poorly understood. Based on the observations made in experimental studies of SARS-CoV and other viral infections, two hypotheses about the routes of viral entry into the CNS have been put forward (Fig. 3).

The first hypothesis assumes that SARS-CoV-2 gets hold of the brain cells by breaching the blood-brain barrier. Endothelial cells of the blood vessels express ACE2 at a relatively high level, which enables efficient virus replication in the circulatory system [75]. SARS-CoV-2-mediated downregulation of ACE2 may increase the permeability of the endothelium via interfering with AngII/Ang1-7 balance and by the bradykinin-kallikrein pathway $[97,98]$. Additionally, SARS-CoV-2 invasion causes the release of cytokines which induce structural and functional alterations of the BBB, resulting in damage to its integrity and permeability. This means that uncontrolled increase of pro-inflammatory factors secretion makes the vessel wall more easily penetrable, and leads to disruption of the blood-brain barrier [99]. Moreover, SARS-CoV-2 can reach the brain directly through a paracellular route or within the immune cells, such as macrophages [100].

According to the second hypothesis, infection of peripheral nerves and retrograde axonal transport is proposed as the route by which SARS-CoV-2 could enter the CNS. The virus may use the olfactory nerve innervating the olfactory epithelium to reach the olfactory bulb and then spread to different areas of the brain. Many COVID-19 patients have been reported to have hyposmia and anosmia, suggesting that SARS-CoV-2 affects the olfactory route [30, 101]. Several pieces of evidence circumstantiate the hypothesis that SARS$\mathrm{CoV}-2$ enters the brain via the olfactory route. Firstly, it has been demonstrated that mouse, non-human primate, and human olfactory mucosa express two key proteins involved in SARS-CoV-2 entry, ACE2 and TMPRSS2 [102]. Secondly, expression of NRP-1 in the epithelial surface layer of the human respiratory and olfactory epithelium has been confirmed by immunostaining of human post mortem tissue [24]. Infection of transgenic mice through intranasal inoculation revealed that both SARS-CoV and MERS-CoV entered the brain via the olfactory nerves and then spread to some brain 
areas such as the thalamus and brainstem [103, 104]. In an animal model, human coronavirus $\mathrm{HCoV}-\mathrm{OC} 43$ was shown to reach the CNS through the olfactory tract, probably along the olfactory nerve [105]. Moreover, mouse hepatitis virus strain JHM (MHV-JHM) was demonstrated by in situ hybridisation to enter the CNS using the trigeminal and olfactory nerves [106]. Based on experience of other respiratory viruses, such as influenza $\mathrm{A}$, retrograde axonal transport in the vagus nerve is also suggested as the SARS-CoV-2 gateway to the brain [107]. The vagus nerve is sometimes referred to as the lung-gut-brain axis as it connects the inner organs, such as the gut, liver, heart, and lungs, with the brain [108]. The terminals of this nerve reach the sites facilitating viral infection and replication, namely ileal epithelial cells with high ACE2 expression [56] and enteric neurons coexpressing ACE2 and TMPRSS2 [109]. At these sites, SARS-CoV-2 may invade peripheral nerve terminals, spread retrogradely along nerve synapses, and gain access to the CNS. Transsynaptic transfer of a virus has been demonstrated for several CoVs, including $\mathrm{HCoV}-\mathrm{OC} 43$, haemagglutinating encephalomyelitis virus67 (HEV67), and avian bronchitis virus (IBV) [110].

It is also possible that SARS-CoV-2 can reach the CNS via both of the aforementioned mechanisms.

\section{Conclusions}

The clinical phenotype of COVID-19 encompasses a spectrum of extrapulmonary manifestations including neurological symptoms. There is substantial evidence that SARS-CoV-2 can invade the CNS leading to its direct damage. This is in addition to indirect mechanisms, such as cytokine storm-induced neuroinflammation or mechanisms related to pulmonary failure hypoxia.

It should also be pointed out that, aside from the neurological symptoms in the acute phase of COVID-19, SARS$\mathrm{CoV}-2$ may be responsible for delayed effects and might even lead to the development of neurodegenerative diseases in the chronic phase of infection. There is an urgent need to increase efforts understand the neuropathological potential of SARS$\mathrm{CoV}-2$ so as to implement proper prevention, diagnosis, and therapeutic decision making.

Acknowledgements: The author thanks Dr Piotr Kruszynski for assistance in preparing the figures.

Funding: This work was supported by Medical University of Silesia in Katowice grant no PCN-1-166/K/0/F.

Conflict of interest: None.

\section{References}

1. Hui DS, I Azhar E, Madani TA, et al. The continuing 2019-nCoV epidemic threat of novel coronaviruses to global health - The latest 2019 novel coronavirus outbreak in Wuhan, China. Int J Infect Dis. 2020; 91: 264-266, doi: 10.1016/j.ijid.2020.01.009, indexed in Pubmed: 31953166.
2. Coronavirus disease (COVID-19) pandemic. https://www.who.int/ emergencies/diseases/novel-coronavirus-2019.

3. WHO Coronavirus (COVID-19) Dashboard With Vaccination Data. https://covid19.who.int/.

4. Wahba L, Jain N, Fire AZ, et al. A pneumonia outbreak associated with a new coronavirus of probable bat origin. Nature. 2020; 579(7798): 270-273, doi: 10.1038/s41586-020-2012-7, indexed in Pubmed: 32015507.

5. Chen N, Zhou M, Dong X, et al. Epidemiological and clinical characteristics of 99 cases of 2019 novel coronavirus pneumonia in Wuhan, China: a descriptive study. The Lancet. 2020; 395(10223): 507-513, doi: 10.1016/s0140-6736(20)30211-7.

6. Wang D, Hu Bo, Hu C, et al. Clinical characteristics of 138 hospitalized patients with 2019 novel coronavirus-infected pneumonia in Wuhan, China. JAMA. 2020; 323(11): 1061-1069, doi: 10.1001/ jama.2020.1585, indexed in Pubmed: 32031570.

7. Huang $\mathrm{C}$, Wang $\mathrm{Y}$, Li X, et al. Clinical features of patients infected with 2019 novel coronavirus in Wuhan, China. The Lancet. 2020; 395(10223): 497-506, doi: 10.1016/s0140-6736(20)30183-5, indexed in Pubmed: 31986264.

8. Moein ST, Hashemian SM, Mansourafshar B, et al. Smell dysfunction: a biomarker for COVID-19. Int Forum Allergy Rhinol. 2020; 10(8): 944-950, doi: 10.1002/alr.22587, indexed in Pubmed: 32301284.

9. Wu JT, Leung K, Bushman M, et al. Estimating clinical severity of COVID-19 from the transmission dynamics in Wuhan, China. Nat Med. 2020; 26(4): 506-510, doi: 10.1038/s41591-020-0822-7, indexed in Pubmed: 32284616.

10. Yang $X, Y u Y, X u J$, et al. Clinical course and outcomes of critically ill patients with SARS-CoV-2 pneumonia in Wuhan, China: a single-centered, retrospective, observational study. The Lancet Respiratory Medicine. 2020; 8(5): 475-481, doi: 10.1016/s2213-2600(20)300795, indexed in Pubmed: 32105632.

11. International Committee on Taxonomy of Viruses. https://talk. ictvonline.org/.

12. Bratosiewicz-Wąsik J, Wąsik TJ. Does virus-receptor interplay influence human coronaviruses infection outcome? Med Sci Monit. 2020; 26: e928572, doi: 10.12659/MSM.928572, indexed in Pubmed: 33311429.

13. Naqvi AA, Fatima K, Mohammad T, et al. Insights into SARS-CoV-2 genome, structure, evolution, pathogenesis and therapies: Structural genomics approach. Biochim Biophys Acta Mol Basis Dis. 2020; 1866(10): 165878, doi: 10.1016/j.bbadis.2020.165878, indexed in Pubmed: 32544429.

14. Zhang YZ, Holmes EC. A genomic perspective on the origin and emergence of SARS-CoV-2. Cell. 2020; 181(2): 223-227, doi: 10.1016/j. cell.2020.03.035, indexed in Pubmed: 32220310.

15. McBride R, van Zyl M, Fielding BC. The coronavirus nucleocapsid is a multifunctional protein. Viruses. 2014; 6(8): 2991-3018, doi: 10.3390/v6082991, indexed in Pubmed: 25105276.

16. Hoffmann M, Kleine-Weber $\mathrm{H}$, Schroeder S, et al. SARS-CoV-2 cell entry depends on ACE2 and TMPRSS2 and is blocked by a clinically proven protease inhibitor. Cell. 2020; 181(2): 271-280.e8, doi: 10.1016/j.cell.2020.02.052, indexed in Pubmed: 32142651.

17. Padmanabhan P, Desikan R, Dixit NM. Targeting TMPRSS2 and Cathepsin $B / L$ together may be synergistic against SARS-CoV-2 infection. PLoS Comput Biol. 2020; 16(12): e1008461, doi: 10.1371/journal. pcbi.1008461, indexed in Pubmed: 33290397.

18. Chen Yu, Liu Q, Guo D. Emerging coronaviruses: Genome structure, replication, and pathogenesis. J Med Virol. 2020; 92(10): 2249, doi: 10.1002/jmv.26234, indexed in Pubmed: 32881013. 
19. Fehr AR, Perlman S. Coronaviruses: an overview of their replication and pathogenesis. Methods Mol Biol. 2015; 1282: 1-23, doi: 10.1007/978-1-4939-2438-7_1, indexed in Pubmed: 25720466.

20. Walls AC, Park YJ, Tortorici MA, et al. Structure, function, and antigenicity of the SARS-CoV-2 spike glycoprotein. Cell. 2020; 181(2): 281292.e6, doi: 10.1016/j.cell.2020.02.058, indexed in Pubmed: 32155444.

21. Fuentes-Prior P. Priming of SARS-CoV-2 S protein by several membrane-bound serine proteinases could explain enhanced viral infectivity and systemic COVID-19 infection. J Biol Chem. 2021; 296: 100135, doi: 10.1074/jbc.REV120.015980, indexed in Pubmed: 33268377.

22. Tang T, Jaimes JA, Bidon MK, et al. Proteolytic activation of SARS-CoV-2 spike at the S1/S2 boundary: potential role of proteases beyond furin. ACS Infect Dis. 2021; 7(2): 264-272, doi: 10.1021/ acsinfecdis.0c00701, indexed in Pubmed: 33432808.

23. Heald-Sargent T, Gallagher T. Ready, set, fuse! The coronavirus spike protein and acquisition of fusion competence. Viruses. 2012; 4(4): 557-580, doi: 10.3390/v4040557, indexed in Pubmed: 22590686.

24. Cantuti-Castelvetri L, Ojha R, Pedro LD, et al. Neuropilin-1 facilitates SARS-CoV-2 cell entry and infectivity. Science. 2020; 370(6518): 856-860, doi: 10.1126/science.abd2985, indexed in Pubmed: 33082293.

25. Davies J, Randeva HS, Chatha K, et al. Neuropilin1 as a new potential SARSCoV2 infection mediator implicated in the neurologic features and central nervous system involvement of COVID19. Mol Med Rep. 2020; 22(5): 4221-4226, doi: 10.3892/mmr.2020.11510, indexed in Pubmed: 33000221.

26. Wang Ke, Chen W, Zhang Z, et al. CD147-spike protein is a novel route for SARS-CoV-2 infection to host cells. Signal Transduct Target Ther. 2020; 5(1): 283, doi: 10.1038/s41392-020-00426-x, indexed in Pubmed: 33277466.

27. Qiao J, Li W, Bao J, et al. The expression of SARS-CoV-2 receptor ACE2 and CD147, and protease TMPRSS2 in human and mouse brain cells and mouse brain tissues. Biochem Biophys Res Commun. 2020; 533(4): 867-871, doi: 10.1016/j.bbrc.2020.09.042, indexed in Pubmed: 33008593.

28. Wnuk M, Sawczyńska K, Kęsek T, et al. Neurological symptoms in hospitalised patients with COVID-19 and their association with in-hospital mortality. Neurol Neurochir Pol. 2021; 55(3): 314-321, doi: 10.5603/PJNNS.a2021.0039, indexed in Pubmed: 34037979.

29. Xiong W, Mu J, Guo J, et al. New onset neurologic events in people with COVID-19 in 3 regions in China. Neurology. 2020; 95(11): e1479e1487, doi: 10.1212/WNL.0000000000010034, indexed in Pubmed: 32554771.

30. Mao L, Jin $\mathrm{H}$, Wang $M$, et al. Neurologic manifestations of hospitalized patients with coronavirus disease 2019 in Wuhan, China. JAMA Neurol. 2020; 77(6): 683-690, doi: 10.1001/jamaneurol.2020.1127, indexed in Pubmed: 32275288.

31. Helms J, Kremer S, Merdji $\mathrm{H}$, et al. Neurologic features in severe SARS-CoV-2 infection. N Engl J Med. 2020; 382(23): 2268-2270, doi: 10.1056/NEJMc2008597, indexed in Pubmed: 32294339.

32. Kandemirli SG, Dogan L, Sarikaya ZT, et al. Brain MRI findings in patients in the Intensive Care Unit with COVID-19 infection. Radiology. 2020; 297(1): E232-E235, doi: 10.1148/radiol.2020201697, indexed in Pubmed: 32384020.

33. Keyhanian K, Umeton RP, Mohit B, et al. SARS-CoV-2 and nervous system: From pathogenesis to clinical manifestation. J Neuroimmunol.
2020 [Epub ahead of print]; 350: 577436, doi: 10.1016/j.jneuroim.2020.577436, indexed in Pubmed: 33212316.

34. Wnuk M, Sawczyńska K, Kęsek T, et al. Neurological symptoms in hospitalised patients with COVID-19 and their association with in-hospital mortality. Neurol Neurochir Pol. 2021; 55(3): 314-321, doi: 10.5603/PJNNS.a2021.0039, indexed in Pubmed: 34037979.

35. Stachura T, Celejewska-Wójcik N, Polok K, et al. A clinical profile and factors associated with severity of the disease among Polish patients hospitalized due to COVID-19 - an observational study. Adv Respir Med. 2021; 89(2): 124-134, doi: 10.5603/ARM.a2021.0035, indexed in Pubmed: 33966260.

36. Mania A, Mazur-Melewska K, Lubarski K, et al. Wide spectrum of clinical picture of COVID-19 in children - From mild to severe disease. J Infect Public Health. 2021; 14(3): 374-379, doi: 10.1016/j. jiph.2020.12.029, indexed in Pubmed: 33621800.

37. Przytuła F, Błądek S, Sławek J. Two COVID-19-related video-accompanied cases of severe ataxia-myoclonus syndrome. Neurol Neurochir Pol. 2021; 55(3): 310-313, doi: 10.5603/PJNNS.a2021.0036, indexed in Pubmed: 34096013.

38. Krajewski PK, Maj J, Szepietowski JC. Cutaneous hyperaesthesia in SARS-CoV-2 infection: rare but not unique clinical manifestation. Acta Derm Venereol. 2021; 101(1): adv00366, doi: 10.2340/000155553729, indexed in Pubmed: 33320278.

39. Fodoulian L, Tuberosa J, Rossier D, et al. SARS-CoV-2 receptors and entry genes are expressed in the human olfactory neuroepithelium and brain. iScience. 2020; 23(12): 101839, doi: 10.1016/j. isci.2020.101839, indexed in Pubmed: 33251489.

40. Baig AM, Khaleeq A, Ali U, et al. Evidence of the COVID-19 virus targeting the CNS: tissue distribution, host-virus interaction, and proposed neurotropic mechanisms. ACS Chem Neurosci. 2020; 11(7): 995-998, doi: 10.1021/acschemneuro.0c00122, indexed in Pubmed: 32167747.

41. Ding $\mathrm{Y}, \mathrm{He} \mathrm{Li}$, Zhang $\mathrm{Q}$, et al. Organ distribution of severe acute respiratory syndrome (SARS) associated coronavirus (SARS-CoV) in SARS patients: implications for pathogenesis and virus transmission pathways. J Pathol. 2004; 203(2): 622-630, doi: 10.1002/ path.1560, indexed in Pubmed: 15141376.

42. Moriguchi T, Harii N, Goto J, et al. A first case of meningitis/encephalitis associated with SARS-Coronavirus-2. Int J Infect Dis. 2020; 94: 55-58, doi: 10.1016/j.ijid.2020.03.062, indexed in Pubmed: 32251791.

43. Liu JM, Tan BH, Wu S, et al. Evidence of central nervous system infection and neuroinvasive routes, as well as neurological involvement, in the lethality of SARS-CoV-2 infection. J Med Virol. 2021; 93(3): 13041313, doi: 10.1002/jmv.26570, indexed in Pubmed: 33002209.

44. Paniz-Mondolfi A, Bryce C, Grimes Z, et al. Central nervous system involvement by severe acute respiratory syndrome coronavirus-2 (SARS-CoV-2). J Med Virol. 2020; 92(7): 699-702, doi: 10.1002/ jmv.25915, indexed in Pubmed: 32314810.

45. Puelles VG, Lütgehetmann M, Lindenmeyer MT, et al. Multiorgan and Renal Tropism of SARS-CoV-2. N Engl J Med. 2020; 383(6): 590-592, doi: 10.1056/NEJMc2011400, indexed in Pubmed: 32402155.

46. Solomon IH, Normandin E, Bhattacharyya S, et al. Neuropathological features of Covid-19. N Engl J Med. 2020; 383(10): 989-992, doi: 10.1056/NEJMc2019373, indexed in Pubmed: 32530583.

47. Tiwari SK, Wang S, Smith D, et al. Revealing tissue-specific SARS-CoV-2 infection and host responses using human stem cell-derived lung and cerebral organoids. Stem Cell Reports. 2021; 16(3): 437 445, doi: 10.1016/j.stemcr.2021.02.005, indexed in Pubmed: 33631122. 
48. Varga Z, Flammer A, Steiger $P$, et al. Endothelial cell infection and endotheliitis in COVID-19. The Lancet. 2020; 395(10234): 1417-1418, doi: 10.1016/s0140-6736(20)30937-5, indexed in Pubmed: 32325026.

49. Song $E$, Zhang Ce, Israelow B, et al. Neuroinvasion of SARS-CoV-2 in human and mouse brain. J Exp Med. 2021; 218(3), doi: 10.1084/ jem.20202135, indexed in Pubmed: 33433624.

50. Buzhdygan TP, DeOre BJ, Baldwin-Leclair A, et al. The SARS-CoV-2 spike protein alters barrier function in 2D static and $3 D$ microfluidic in-vitro models of the human blood-brain barrier. Neurobiol Dis. 2020; 146: 105131, doi: 10.1016/j.nbd.2020.105131, indexed in Pubmed: 33053430.

51. Chu H, Chan JW, Yuen TT, et al. Comparative tropism, replication kinetics, and cell damage profiling of SARS-CoV-2 and SARS-CoV with implications for clinical manifestations, transmissibility, and laboratory studies of COVID-19: an observational study. The Lancet Microbe. 2020; 1(1): e14-e23, doi: 10.1016/s2666-5247(20)30004-5, indexed in Pubmed: 32835326.

52. Ramani A, Müller L, Ostermann PN, et al. SARS-CoV-2 targets neurons of 3D human brain organoids. EMBO J. 2020; 39(20): e106230, doi: 10.15252/embj.2020106230, indexed in Pubmed: 32876341.

53. Rathnasinghe R, Strohmeier S, Amanat F, et al. Comparison of transgenic and adenovirus hACE2 mouse models for SARS-CoV-2 infection. Emerg Microbes Infect. 2020; 9(1): 2433-2445, doi: 10.1080/22221751.2020.1838955, indexed in Pubmed: 33073694.

54. Zheng J, Wong LYR, Li K, et al. COVID-19 treatments and pathogenesis including anosmia in K18-hACE2 mice. Nature. 2021; 589(7843): 603-607, doi: 10.1038/s41586-020-2943-z, indexed in Pubmed: 33166988.

55. Yinda CK, Port JR, Bushmaker T, et al. K18-hACE2 mice develop respiratory disease resembling severe COVID-19. PLoS Pathog. 2021; 17(1): e1009195, doi: 10.1371/journal.ppat.1009195, indexed in Pubmed: 33465158.

56. Zou X, Chen Ke, Zou J, et al. Single-cell RNA-seq data analysis on the receptor ACE2 expression reveals the potential risk of different human organs vulnerable to 2019-nCoV infection. Front Med. 2020; 14(2): 185-192, doi: 10.1007/s11684-020-0754-0, indexed in Pubmed: 32170560.

57. Chen R, Wang K, Yu J, et al. The spatial and cell-type distribution of SARS-CoV-2 receptor ACE2 in the human and mouse brains. Front Neurol. 2020; 11: 573095, doi: 10.3389/fneur.2020.573095, indexed in Pubmed: 33551947.

58. Lukiw WJ, Pogue A, Hill JM. SARS-CoV-2 infectivity and neurological targets in the brain. Cell Mol Neurobiol. 2020 [Epub ahead of print], doi: 10.1007/s10571-020-00947-7, indexed in Pubmed: 32840758.

59. Gironacci MM, Cerniello FM, Longo Carbajosa NA, et al. Protective axis of the renin-angiotensin system in the brain. Clin Sci (Lond). 2014; 127(5): 295-306, doi: 10.1042/CS20130450, indexed in Pubmed: 24827941.

60. Kuba K, Imai Y, Rao S, et al. A crucial role of angiotensin converting enzyme 2 (ACE2) in SARS coronavirus-induced lung injury. Nat Med. 2005; 11(8): 875-879, doi: 10.1038/nm1267, indexed in Pubmed: 16007097.

61. Xu P, Sriramula S, Lazartigues E. ACE2/ANG-(1-7)/Mas pathway in the brain: the axis of good. Am J Physiol Regul Integr Comp Physiol. 2011; 300(4): R804-R817, doi: 10.1152/ajpregu.00222.2010, indexed in Pubmed: 21178125.
62. Chen Ji, Zhao Y, Chen S, et al. Neuronal over-expression of ACE2 protects brain from ischemia-induced damage. Neuropharmacology. 2014; 79: 550-558, doi: 10.1016/j.neuropharm.2014.01.004, indexed in Pubmed: 24440367.

63. Peña Silva RA, Chu Yi, Miller JD, et al. Impact of ACE2 deficiency and oxidative stress on cerebrovascular function with aging. Stroke. 2012; 43(12): 3358-3363, doi: 10.1161/STROKEAHA.112.667063, indexed in Pubmed: 23160880.

64. Fumagalli S, Perego C, Pischiutta F, et al. The ischemic environment drives microglia and macrophage function. Front Neurol. 2015; 6: 81, doi: 10.3389/fneur.2015.00081, indexed in Pubmed: 25904895.

65. Mukerji SS, Solomon IH. What can we learn from brain autopsies in COVID-19? Neurosci Lett. 2021; 742: 135528, doi: 10.1016/j.neulet.2020.135528, indexed in Pubmed: 33248159.

66. Reichard RR, Kashani KB, Boire NA, et al. Neuropathology of COVID-19: a spectrum of vascular and acute disseminated encephalomyelitis (ADEM)-like pathology. Acta Neuropathol. 2020; 140(1): 1-6, doi: 10.1007/s00401-020-02166-2, indexed in Pubmed: 32449057.

67. Pezzini A, Padovani A. Lifting the mask on neurological manifestations of COVID-19. Nat Rev Neurol. 2020; 16(11): 636-644, doi: 10.1038/s41582-020-0398-3, indexed in Pubmed: 32839585.

68. Hess DC, Eldahshan W, Rutkowski E. COVID-19-related stroke. Trans Stroke Res. 2020; 11(3): 322-325, doi: 10.1007/s12975-02000818-9, indexed in Pubmed: 32378030.

69. Tang N, Li D, Wang X, et al. Abnormal coagulation parameters are associated with poor prognosis in patients with novel coronavirus pneumonia. J Thromb Haemost. 2020; 18(4): 844-847, doi: 10.1111/ jth.14768, indexed in Pubmed: 32073213.

70. Zhou F, Yu T, Du R, et al. Clinical course and risk factors for mortality of adult inpatients with COVID-19 in Wuhan, China: a retrospective cohort study. The Lancet. 2020; 395(10229): 1054-1062, doi: 10.1016/ s0140-6736(20)30566-3, indexed in Pubmed: 32171076.

71. Mehra MR, Desai SS, Kuy S, et al. Cardiovascular disease, drug therapy, and mortality in Covid-19. N Engl J Med. 2020; 382(25): e102, doi: 10.1056/NEJMoa2007621, indexed in Pubmed: 32356626

72. Katal S, Balakrishnan S, Gholamrezanezhad A. Neuroimaging and neurologic findings in COVID-19 and other coronavirus infections: A systematic review in 116 patients. J Neuroradiol. 2021; 48(1): 43-50, doi: 10.1016/j.neurad.2020.06.007, indexed in Pubmed: 32603770 .

73. Paterson RW, Brown RL, Benjamin L, et al. The emerging spectrum of COVID-19 neurology: clinical, radiological and laboratory findings. Brain. 2020; 143(10): 3104-3120, doi: 10.1093/brain/awaa240, indexed in Pubmed: 32637987.

74. Iba T, Warkentin TE, Thachil J, et al. Proposal of the definition for COVID-19-associated coagulopathy. J Clin Med. 2021; 10(2), doi: 10.3390/jcm10020191, indexed in Pubmed: 33430431.

75. Hamming I, Timens W, Bulthuis MLC, et al. Tissue distribution of ACE2 protein, the functional receptor for SARS coronavirus. A first step in understanding SARS pathogenesis. J Pathol. 2004; 203(2): 631-637, doi: 10.1002/path.1570, indexed in Pubmed: 15141377.

76. Valderrama EV, Humbert K, Lord A, et al. Severe acute respiratory syndrome coronavirus 2 infection and ischemic stroke. Stroke. 2020; 51(7): e124-e127, doi: 10.1161/STROKEAHA.120.030153, indexed in Pubmed: 32396456.

77. Zhang B, Zhou X, Qiu Y, et al. Clinical characteristics of 82 cases of death from COVID-19. PLoS One. 2020; 15(7): e0235458, 
doi: 10.1371/journal.pone.0235458, indexed in Pubmed: 32645044.

78. Zuo Yu, Zuo M, Yalavarthi S, et al. Neutrophil extracellular traps and thrombosis in COVID-19. J Thromb Thrombolysis. 2021; 51(2): 446453, doi: 10.1007/s11239-020-02324-z, indexed in Pubmed: 33151461.

79. Pfeiler S, Massberg S, Engelmann B. Biological basis and pathological relevance of microvascular thrombosis. Thromb Res. 2014; 133 Suppl 1: S35-S37, doi: 10.1016/j.thromres.2014.03.016, indexed in Pubmed: 24759139.

80. Haidar MA, Jourdi H, Haj Hassan Z, et al. Neurological and neuropsychological changes associated with SARS-CoV-2 infection: new observations, new mechanisms. Neuroscientist. 2021 [Epub ahead of print]: 1073858420984106, doi: 10.1177/1073858420984106, indexed in Pubmed: 33393420.

81. Tisoncik JR, Korth MJ, Simmons CP, et al. Into the eye of the cytokine storm. Microbiol Mol Biol Rev. 2012; 76(1): 16-32, doi: 10.1128/ MMBR.05015-11, indexed in Pubmed: 22390970.

82. Li Y, Fu Li, Gonzales DM, et al. Coronavirus neurovirulence correlates with the ability of the virus to induce proinflammatory cytokine signals from astrocytes and microglia. J Virol. 2004; 78(7): 3398-3406, doi: 10.1128/ jvi.78.7.3398-3406.2004, indexed in Pubmed: 15016862.

83. Banks WA, Freed EO, Wolf KM, et al. Transport of human immunodeficiency virus type 1 pseudoviruses across the blood-brain barrier: role of envelope proteins and adsorptive endocytosis. J Virol. 2001; 75(10): 4681-4691, doi: 10.1128/JVI.75.10.4681-4691.2001, indexed in Pubmed: 11312339.

84. Erickson MA, Banks WA. Neuroimmune axes of the blood-brain barriers and blood-brain interfaces: bases for physiological regulation, disease states, and pharmacological interventions. Pharmacol Rev. 2018; 70(2): 278-314, doi: 10.1124/pr.117.014647, indexed in Pubmed: 29496890.

85. Heneka MT, Golenbock D, Latz E, et al. Immediate and long-term consequences of COVID-19 infections for the development of neurological disease. Alzheimers Res Ther. 2020; 12(1):69, doi: 10.1186/ s13195-020-00640-3, indexed in Pubmed: 32498691.

86. Lindlau A, Widmann CN, Putensen C, et al. Predictors of hippocampal atrophy in critically ill patients. Eur J Neurol. 2015; 22(2): 410-415, doi: 10.1111/ene.12443, indexed in Pubmed: 24724819.

87. Dantzer R. Neuroimmune interactions: from the brain to the immune system and vice versa. Physiol Rev. 2018; 98(1): 477-504, doi: 10.1152/physrev.00039.2016, indexed in Pubmed: 29351513.

88. Najjar S, Pahlajani S, De Sanctis V, et al. Neurovascular unit dysfunction and blood-brain barrier hyperpermeability contribute to schizophrenia neurobiology: a theoretical integration of clinical and experimental evidence. Front Psychiatry. 2017; 8: 83, doi: 10.3389/ fpsyt.2017.00083, indexed in Pubmed: 28588507.

89. de Candia P, Prattichizzo F, Garavelli S, et al. T Cells: Warriors of SARS-CoV-2 Infection. Trends Immunol. 2021; 42(1): 18-30, doi: 10.1016/j.it.2020.11.002, indexed in Pubmed: 33277181.

90. Xu Z, Shi L, Wang Y, et al. Pathological findings of COVID-19 associated with acute respiratory distress syndrome. The Lancet Respiratory Medicine. 2020; 8(4): 420-422, doi: 10.1016/s2213-2600(20)30076-x, indexed in Pubmed: 32085846.

91. Song JW, Zhang C, Fan X, et al. Immunological and inflammatory profiles in mild and severe cases of COVID-19. Nat Commun. 2020; 11(1): 3410, doi: 10.1038/s41467-020-17240-2, indexed in Pubmed: 32641700 .
92. Diao Bo, Wang C, Tan Y, et al. Reduction and functional exhaustion of T cells in patients with coronavirus disease 2019 (COVID-19). Front Immunol. 2020; 11: 827, doi: 10.3389/fimmu.2020.00827, indexed in Pubmed: 32425950.

93. Zheng $M$, Gao $Y$, Wang $G$, et al. Functional exhaustion of antiviral lymphocytes in COVID-19 patients. Cell Mol Immunol. 2020; 17(5): 533-535, doi: 10.1038/s41423-020-0402-2, indexed in Pubmed: 32203188.

94. Wu GF, Dandekar AA, Pewe L, et al. The role of CD4 and CD8 T cells in MHV-JHM-induced demyelination. Adv Exp Med Biol. 2001; 494: 341-347, doi: 10.1007/978-1-4615-1325-4_51, indexed in Pubmed: 11774490.

95. Hung ECW, Chim SSC, Chan PKS, et al. Detection of SARS coronavirus RNA in the cerebrospinal fluid of a patient with severe acute respiratory syndrome. Clin Chem. 2003; 49(12): 2108-2109, doi: 10.1373/ clinchem.2003.025437, indexed in Pubmed: 14633896.

96. Yeh EA, Collins A, Cohen ME, et al. Detection of coronavirus in the central nervous system of a child with acute disseminated encephalomyelitis. Pediatrics. 2004; 113(1 Pt 1): e73-e76, doi: 10.1542/ peds.113.1.e73, indexed in Pubmed: 14702500.

97. Guo S, Som AT, Arai K, et al. Effects of angiotensin-II on brain endothelial cell permeability via PPARalpha regulation of para- and trans-cellular pathways. Brain Res. 2019; 1722: 146353, doi: 10.1016/j. brainres.2019.146353, indexed in Pubmed: 31356784.

98. Sodhi CP, Wohlford-Lenane C, Yamaguchi Y, et al. Attenuation of pulmonary ACE2 activity impairs inactivation of des-Arg bradykinin/ BKB1R axis and facilitates LPS-induced neutrophil infiltration. Am J Physiol Lung Cell Mol Physiol. 2018; 314(1): L17-L31, doi: 10.1152/ ajplung.00498.2016, indexed in Pubmed: 28935640.

99. Kempuraj D, Selvakumar GP, Ahmed ME, et al. COVID-19, mast cells, cytokine storm, psychological stress, and neuroinflammation. Neuroscientist. 2020; 26(5-6): 402-414, doi: 10.1177/1073858420941476, indexed in Pubmed: 32684080.

100. Park MD. Macrophages: a Trojan horse in COVID-19? Nat Rev Immunol. 2020; 20(6): 351, doi: 10.1038/s41577-020-0317-2, indexed in Pubmed: 32303696.

101. Lechien JR, Chiesa-Estomba CM, De Siati DR, et al. Olfactory and gustatory dysfunctions as a clinical presentation of mild-to-moderate forms of the coronavirus disease (COVID-19): a multicenter European study. Eur Arch Otorhinolaryngol. 2020; 277(8): 2251-2261, doi: 10.1007/s00405-020-05965-1, indexed in Pubmed: 32253535.

102. Brann DH, Tsukahara T, Weinreb C, et al. Non-neuronal expression of SARS-CoV-2 entry genes in the olfactory system suggests mechanisms underlying COVID-19-associated anosmia. Sci Adv. 2020; 6(31), doi: 10.1126/sciadv.abc5801, indexed in Pubmed: 32937591.

103. Li K, Wohlford-Lenane C, Perlman S, et al. Middle East respiratory syndrome coronavirus causes multiple organ damage and lethal disease in mice transgenic for human dipeptidyl peptidase 4. J Infect Dis. 2016; 213(5): 712-722, doi: 10.1093/infdis/jiv499, indexed in Pubmed: 26486634.

104. McCray PB, Pewe L, Wohlford-Lenane C, et al. Lethal infection of K18-hACE2 mice infected with severe acute respiratory syndrome coronavirus. J Virol. 2007; 81(2): 813-821, doi: 10.1128/JVI.02012-06, indexed in Pubmed: 17079315.

105. Dubé M, Le Coupanec A, Wong AHM, et al. Axonal transport enables neuron-to-neuron propagation of human coronavirus OC43. J Virol. 
2018; 92(17), doi: 10.1128/JVI.00404-18, indexed in Pubmed: 29925652.

106. Perlman S, Jacobsen G, Afifi A. Spread of a neurotropic murine coronavirus into the CNS via the trigeminal and olfactory nerves. Virology. 1989; 170(2): 556-560, doi: 10.1016/0042-6822(89)90446-7, indexed in Pubmed: 2543129.

107. Matsuda K, Park $\mathrm{CH}$, Sunden $\mathrm{Y}$, et al. The vagus nerve is one route of transneural invasion for intranasally inoculated influenza a virus in mice. Vet Pathol. 2004; 41(2): 101-107, doi: 10.1354/vp.41-2101, indexed in Pubmed: 15017022.

108. Breit S, Kupferberg A, Rogler G, et al. Vagus nerve as modulator of the brain-gut axis in psychiatric and inflammatory disorders. Front
Psychiatry. 2018; 9: 44, doi: 10.3389/fpsyt.2018.00044, indexed in Pubmed: 29593576.

109. Muus C, Luecken MD, Eraslan G, et al. NHLBI LungMap Consortium, Human Cell Atlas Lung Biological Network. Single-cell meta-analysis of SARS-CoV-2 entry genes across tissues and demographics. Nat Med. 2021; 27(3): 546-559, doi: 10.1038/s41591-02001227-z, indexed in Pubmed: 33654293.

110. Zubair AS, McAlpine LS, Gardin T, et al. Neuropathogenesis and neurologic manifestations of the coronaviruses in the age of Coronavirus Disease 2019: A review. JAMA Neurol. 2020; 77(8): 10181027, doi: 10.1001/jamaneurol.2020.2065, indexed in Pubmed: 32469387. 